\title{
Wayang Klithik Robot
}

\section{Gandar Setiawan}

Jurusan Penciptaan Kriya, Program Pascasarjana Institut Seni Indonesia Yogyakarta

Email: gandar_robot@yahoo.com

\begin{abstract}
Wayang is a autentic culture from Indonesia. Wayang has many figure and character. It is main idea of this make the artwork. Inspiration of the artwork also from observation robot forms. Robot has the furious and futuristic form. Like the progression of technologi, form of robot also more experiencing form progression. Until now, form of robot still identic and can not losed from imajinative forms. This prossesing to make the artwork use created methode from Gustami, it is a three stages six steps creating craft artwork. First stage is eksploration consist of observation and finding refference steps. Second stage is desaigning consist of making the sketch and making the gambar teknik or modeling steps. Third stage is forming consist of create artwork and finished with value and evaluation steps. Result of visual form is a three dimension artwork with futuristic robot form. Visual form the artwork is a transformastion of futuristic wayang klithik with robot form. The puppet figures are Wrekudara and Gatotkaca Combination form is a method for impression and aesthete value of the artwork.
\end{abstract}

Keywords: puppet; wayang klithik; robot; Wrekudara; Gatotkaca

\begin{abstract}
Abstrak
Wayang merupakan budaya asli dari Indonesia. Wayang memiliki berbagai macam tokoh dan karakter. Wayang menjadi ide utama dalam penciptaan karya ini. Inspirasi karya juga muncul dari pengamatan bentuk-bentuk robot. Robot memiliki bentuk yang variatif dan futuristik. Sesuai dengan perkembangan teknologi, bentuk robot juga mengalami perkembangan yang lebih bermacam-macam. Sampai saat ini, bentuk robot masih identik dan tidak bisa lepas dari bentuk-bentuk imajinatif. Proses pembuatan karya seni ini menggunakan metode penciptaan dari Gustami, yaitu metode tiga tahap enam langkah dalam menciptakan karya seni kriya. Tahap pertama yaitu eksplorasi yang meliputi langkah pengamatan dan pencarian sumber pustaka. Tahap kedua merupakan tahap perancangan yang terdiri dari langkah pembuatan beberapa sketsa dan pembuatan gambar teknik ataupun model. Tahap yang ketiga yaitu tahap perwujudan yang terdiri langkah pengerjaan karya, dan diakhiri dengan penilaian juga evaluasi karya yang telah jadi. Bentuk visual yang dihasilkan yaitu karya seni tiga dimensi dengan bentuk futuristik menyerupai robot. Bentuk visual karya merupakan penggabungan antara bentuk wayang klithik dengan bentuk robot. Tokoh wayang yang dibuat yaitu Wrekudara dan Gatotkaca. Perpaduan bentuk dilakukan sebagai cara untuk memberikan kesan dan nilai estetik pada karya.

Kata kunci: wayang; wayang klithik; robot; Wrekudara; Gatotkaca
\end{abstract}




\section{Pendahuluan}

Wayang merupakan salah satu budaya asli Indonesia yang identik dengan penggabungan berbagai macam seni di dalamnya. Wayang sebagai salah satu budaya yang adiluhung meliputi penggabungan antara seni kriya, seni sastra, seni tutur, seni peran, dan seni perlambangan (Tim Penulis Senawangi, 1999: 247). Sebagai budaya yang adiluhung, wayang harus selalu dilestarikan agar tetap terjaga eksistensinya. Penciptaan karya ini terinspirasi pada bentuk visual wayang yang memiliki karakter futuristik yang digabungkan dengan bentuk robot, dengan material kayu. Hal ini dilakukan untuk memberikan gaya baru yang akan ditampilkan dalam karya seni. Dalam penciptaan karya ini, tujuan yang ingin dicapai yaitu menciptakan karya dengan ide dasar robot yang digabungkan dengan bentuk wayang, sehingga karya yang dihasilkan berupa wayang klithik. Dengan menggabungkan bentuk wayang dan robot, maka terciptalah nuansa baru antara budaya modern dengan budaya tradisional yang dapat memberikan manfaat edukasi, budaya dan seni.

Robot dikenal sebagai alat yang memiliki fungsi membantu pekerjaan manusia. Banyak negara maju menciptakan robot untuk melakukan hal-hal yang sulit atau beresiko jika dilakukan oleh manusia. Awal munculnya istilah robot berasal dari para ilmuwan biologi dan penulis novel bernama Wright Karel Capek pada tahun 1921 di negara Ceko. Pada waktu itu robot dijadikan simbol perbudakan yang ditampilkan dalam drama pertunjukkan dengan judul Rossum's Universal Robots. Wright Karel Capek menuliskan istilah robot dalam karya tulisannya, dan sejak itu pula kata robot mulai familiar dan dikenal banyak orang. Dalam bahasa Ceko, robot berasal dari kata robota (Lubis, 2013: 1).

Penciptaan ini mengacu pada beberapa teori yang mendukung terwujudnya karya. Teori-teori pendukung dalam proses penciptaan karya ini berkaitan dengan metodologi penciptaan, teori estetika, dan teori tanda. Setiap teori memiliki karakter dan fungsi sendiri-sendiri tetapi masih memiliki keterkaitan antara satu dengan lainnya.

Teori estetika merupakan teori yang berhubungan dengan keindahan sebuah objek.
Estetika adalah segala hal yang berkaitan dengan keindahan (Liang Gie, 1997: 15). Pada penciptaan ini objek yang dimaksudkan adalah karya seni, berkaitan dengan elemen-elemen seni rupa yang akan ditampilkan. Teori lainnya yang dipakai yaitu teori dari Dharsono Sony Kartika, tentang elemenelemen seni rupa yang terdiri dari komposisi garis, bidang, warna, yang dipadukan secara menyatu, selaras, harmoni (Kartika, 2004:12).

Teori tanda atau semiotik yang digunakan dalam penciptaan ini adalah teori dari C.S. Peirce. Peirce menjelaskan tentang hubungan-hubungan tanda yang sering dikenal dengan trikotomi Peirce. Teori ini memuat hubungan tanda dengan tanda, tanda dengan objek, dan tanda dengan penafsir tanda (Berger, 2010: 33). Trikotomi Peirce berisikan tentang hubungan tiga unsur yang saling melengkapi yaitu objek, representamen, dan interpretan (Budiman, 2011: 17). Teori ini berfungsi untuk menunjukkan karakter dari tokoh wayang yang diciptakan.

Metode penciptaan yang digunakan adalah metode penciptaan dari Gustami. "Teori penciptaan Gustami terdiri dari tiga tahap - enam langkah penciptaan seni kriya. Pertama tahap eksplorasi yang meliputi pengamatan, dan pencarian sumber penciptaan. Kedua, tahap perancangan yaitu membuat beberapa sketsa, dan pembuatan gambar teknik. Tahap ketiga, perwujudan yaitu proses pembentukan, dan dilanjutkan penilaian dan evaluasi karya yang telah jadi" (Gustami, 2004: 29-32). Untuk lebih jelasnya dapat dilihat melalui skema 1.

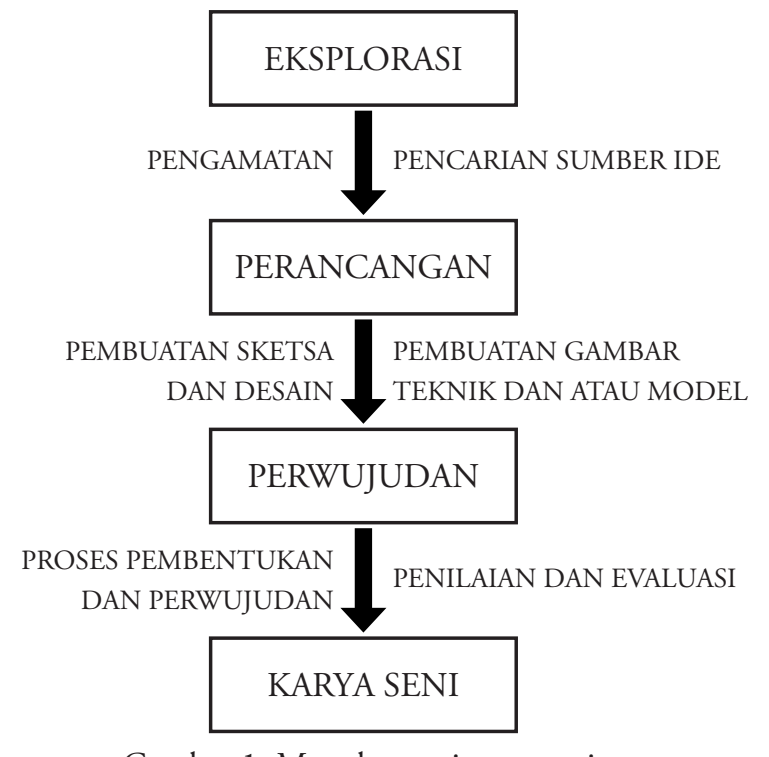

Gambar 1. Metode penciptaan seni. 


\section{Tahap Eksplorasi}

Tahap ini merupakan tahap awal dalam menciptakan karya seni. Pada langkah ini, dilakukan dua tahapan yang terdiri dari pengamatan objek yang dijadikan sumber ide yaitu wayang dan robot, serta pencarian berbagai macam referensi yang berkaitan dengan ide penciptaan. Penciptaan karya ini bersumber dari tokoh wayang dan film tentang robot dengan karakter futuristiknya. Tokoh wayang yang diambil yaitu Wrekudara dan Gatotkaca. Pemilihan tokoh wayang Wrekudara karena dianggap sebagai salah satu tokoh yang tangguh dan kuat, yang memiliki karakter menggunakan dodot polèng bang bintulu dan memiliki senjata kuku pancanaka sebagai anugrah dari keturunan Batara Bayu (Tim Penulis Senawangi, 1999: 291). Bentuk wayang kulit Wrekudara dapat dilihat pada gambar 1 . Gatotkaca dipilih karena memiliki kekuatan yang tidak kalah dengan Wrekudara. Sebagai anak dari Wrekudara, Gatotkaca menjadi tokoh pahlawan dari keluarga Pandawa. Bentuk wayang tokoh Gatotkaca dapat dilihat pada gambar 2 .

Selain terinspirasi oleh tokoh-tokoh wayang, karya yang dibuat juga terinspirasi oleh film tentang robot. Beberapa film tersebut adalah $I$ Robot, Transformers, Real Steel, Astroboy, Pacific Rim, dan masih banyak lagi film-film lainnya.

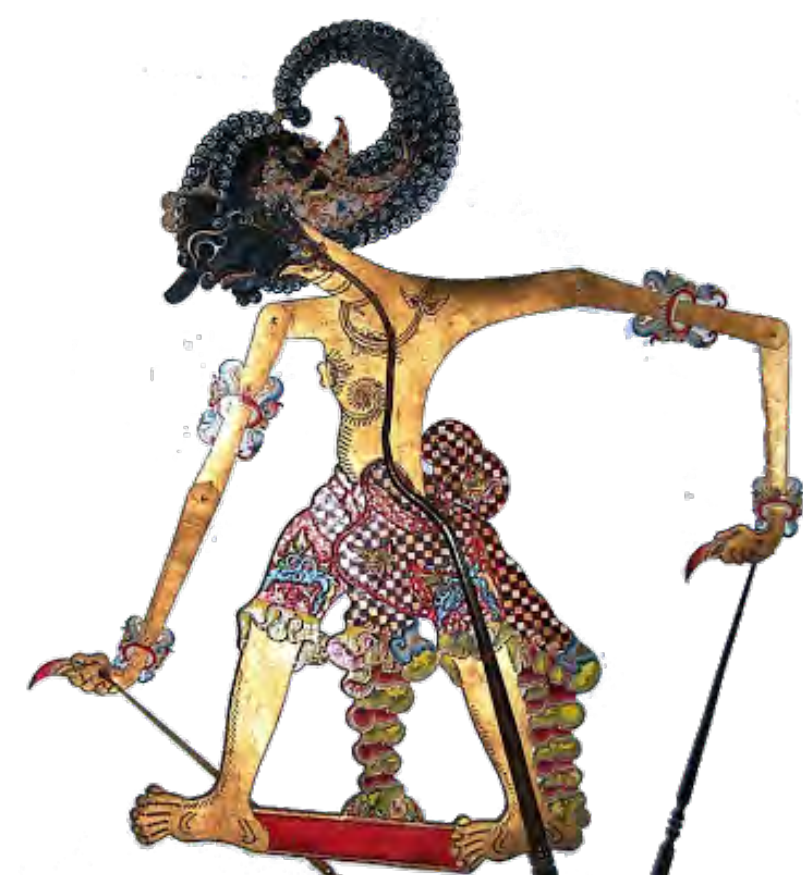

Gambar 1. Tokoh Bima dalam pewayangan gagrak Yogyakarta. (Sumber: http://crowsinside.blogspot.com/p/ laman-unduh.html; diakses pada tanggal 29 November 2014, jam 19.00 WIB)
Bentuk robot dalam film-film ini dapat dilihat pada gambar 3, 4, dan 5. Film-film tersebut menampilkan kecanggihan teknologi yang disimbolkan dalam bentuk robot. Seperti yang ditampilkan dalam beberapa film di atas bahwa robot dijadikan alat untuk melakukan pekerjaan yang sulit dilakukan manusia. Dalam film I Robot memperlihatkan adegan bagaimana sebuah robot humanoid yang mencoba memberikan pertolongan kepada manusia dengan susah payah, penuh resiko, dan dramatis. Hal ini menyimbolkan bahwa teknologi robot dimanfaatkan manusia sebagai alat memenuhi kebutuhan manusia yang sulit dilakukan oleh manusia. Hal ini berkaitan dengan awal munculnya istilah robot, yang menyatakan tiga hukum robot yaitu pertama robot tidak diperbolehkan melukai manusia, atau berdiam diri membiarkan manusia celaka, kedua sebuah robot harus mematuhi perintah yang diberikan oleh manusia kecuali perintah tersebut bertentangan dengan hukum yang pertama, dan ketiga robot harus dapat melindungi dirinya sendiri selama itu tidak bertentangan dengan hukum yang pertama dan hukum kedua.

Selain terinspirasi dari film-film bertema robot, penciptaan ini juga terinspirasi dari bentuk-bentuk robot yang sudah ada. Dari bentuk-bentuk robot yang sudah ada kemudian dikembangkan. Adapun

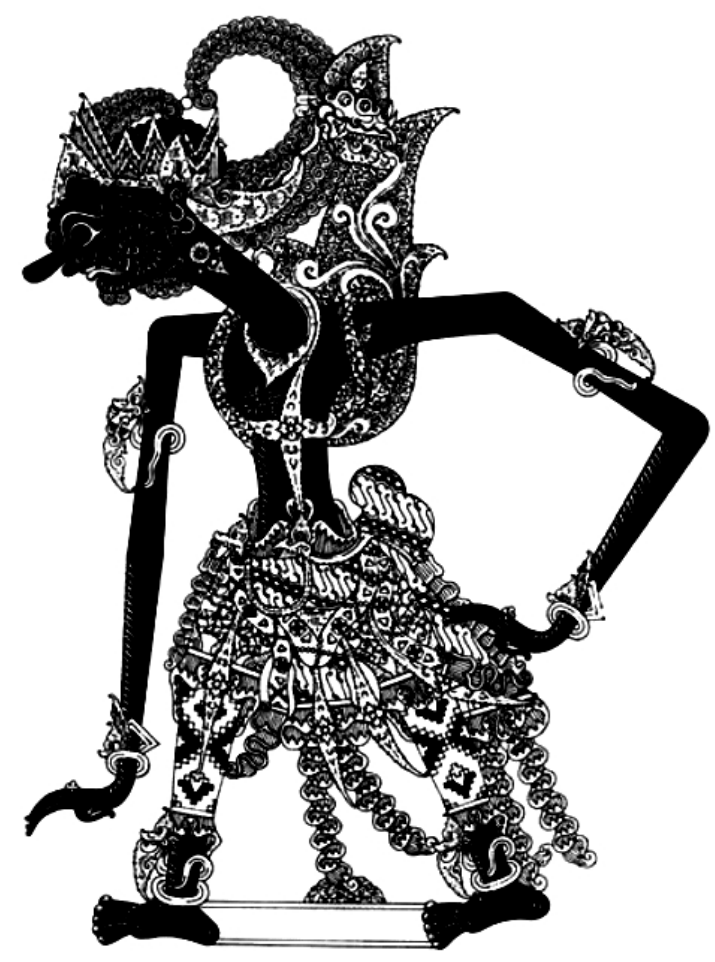

Gambar 2. Tokoh Gatotkaca dalam pewayangan gagrak Surakarta. (Ensiklopedia Wayang Indonesia) 
pengembangan dan hal baru yang ditampilkan dari proses pembuatan karya ini dapat dilihat dari segi konsep, bahan, bentuk, dan fungsinya. Gambar 6, 7, dan 8 adalah gambar-gambar robot dan beberapa karya seni yang berbentuk robot yang menjadi sumber inspirasi.

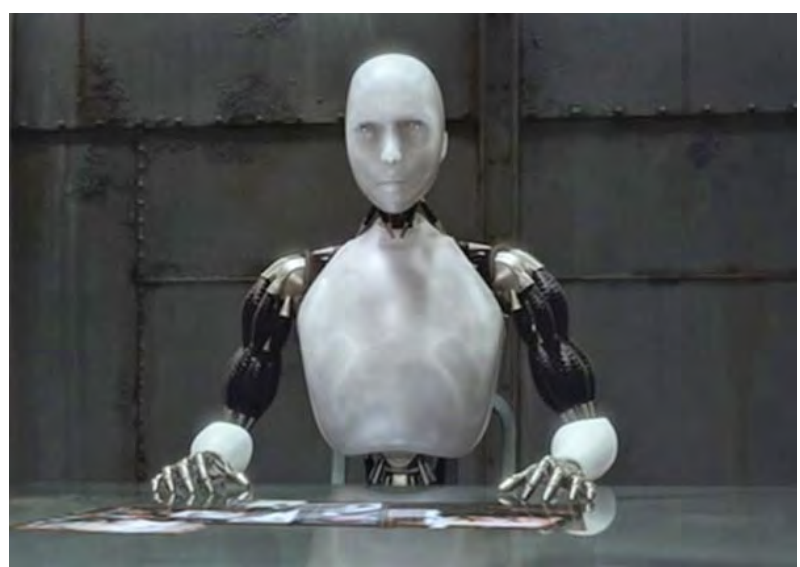

Gambar 3. Bentuk robot dalam film I, Robot.

(Sumber: http://static.comicvine.com/uploads/ original/7/74798/1429066-so.jpg; diakses pada tanggal 23 Oktober 2014, jam 20.00 WIB)

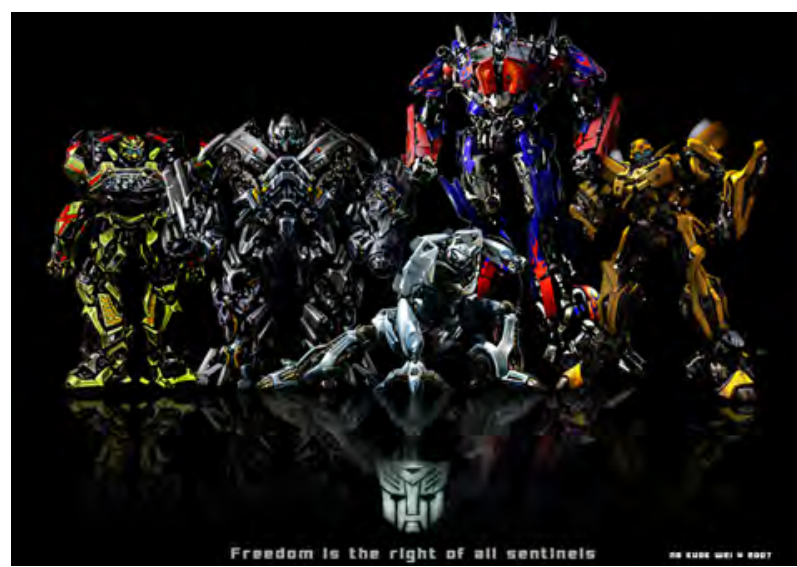

Gambar 4. Bentuk robot dalam film Transformers.

(Sumber: http://lostbrosclubhouse.com/wpcontent/ uploads/2014/07/transformers_autobots_by_megavalve.jpg; diakses pada tanggal 23 Oktober 2014, jam 20.00 WIB)

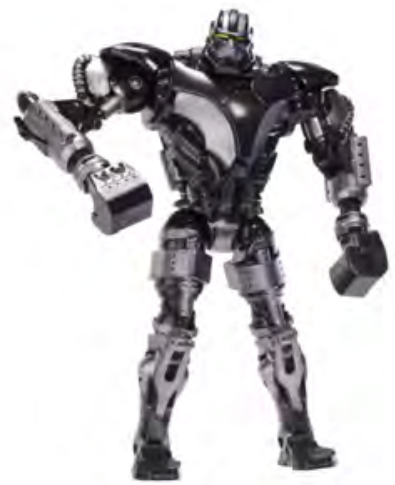

Gambar 5. Bentuk robot dalam film Real Steel.

(Sumber: http://ecx.images-amazon.com/images/ I/81AUEQixLmL._SL1500_.jpg; diakses pada tanggal 23 Oktober 2014, jam 20.00 WIB)

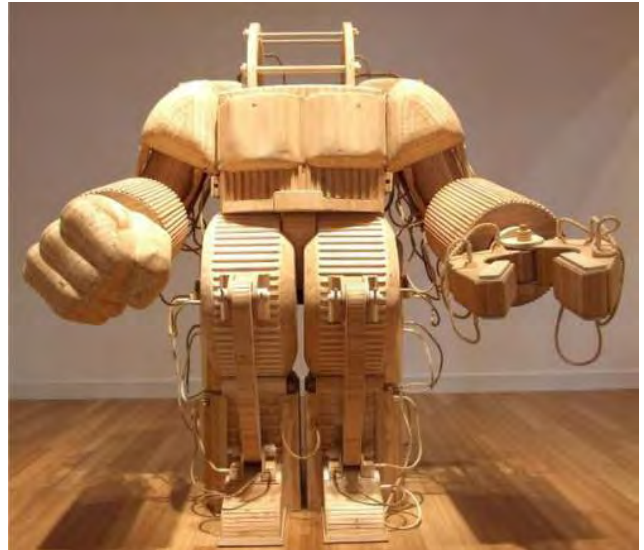

Gambar 6. Karya patung berbentuk robot.

(Sumber: http://www.smosh.com/smosh-pit/photos/25amazing-wood-sculptures; diakses pada tanggal 23 Oktober 2014, jam 20.00 WIB)

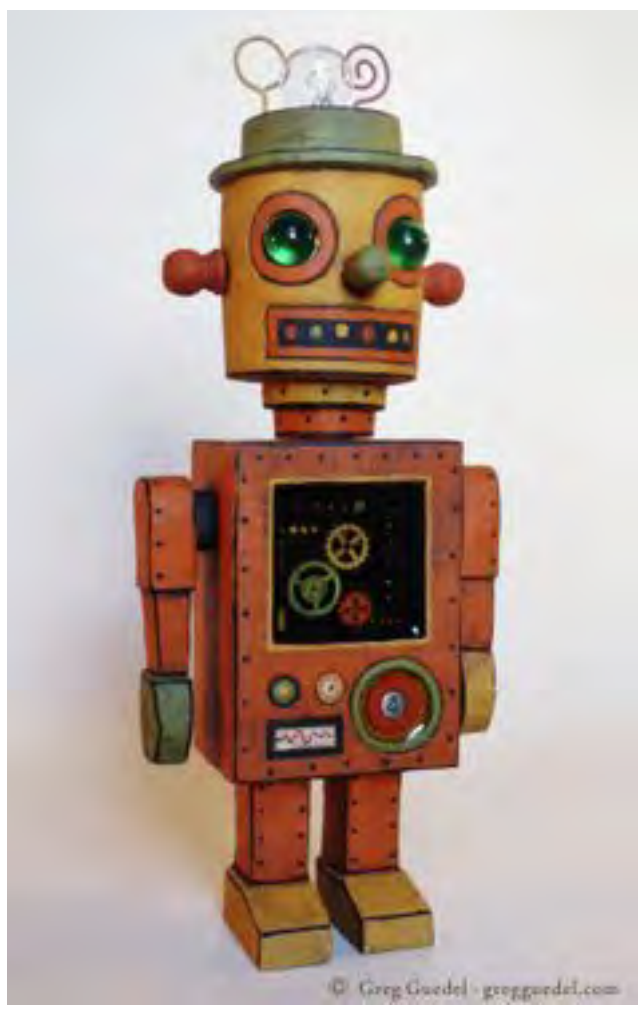

Gambar 7. Karya patung berbentuk robot.

(Sumber: http://media-cache-ak0.pinimg.com/236x/e4/c5/ ba/e4c5ba436869041d732f34dc3861bca8.jpg; diakses pada tanggal 23 Oktober 2014, jam 20.00 WIB
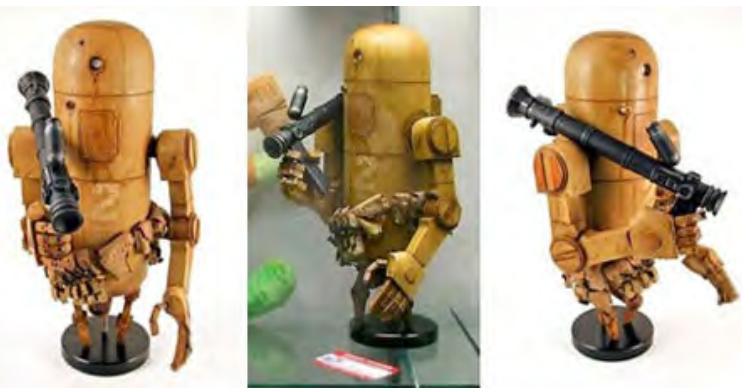

Gambar 8. Karya kerajinan berbentuk robot.

(Sumber: http://gadgets.boingboing.net/2007/08/31/ashleywoods-bertie.html; diakses pada tanggal 23 Oktober 2014) 


\section{Tahap Perancangan}

Tahap perancangan merupakan tahap pembuatan sketsa dan desain. Desain dibuat agar bentuk yang diinginkan lebih terpetakan. Dengan menggunakan sketsa dan desain sebagai acuan, akan mempermudah mewujudkannya. Hal ini juga memberikan peluang untuk memunculkan ide lain ditinjau dari segi bentuk yang akan diwujudkan. Langkah selanjutnya setelah membuat sketsa dan desain adalah pembuatan model potongan pola. Langkah ini dilakukan untuk memastikan ketepatan desain dan bentuk yang akan disesuaikan dengan konstruksi dan komposisi bentuk.

Dalam perancangan karya ini dihasilkan 3 desain alternatif dan model potongan pola. Ketiga desain alternatif dan model potongan pola dapat dilihat pada gambar 9, 10, 11, dan 12 .

\section{Tahap Perwujudan}

Setelah membuat sketsa dan desain kemudian dilanjutkan pembuatan model potongan pola, tahap berikutnya adalah mewujudkannya. Langkah-

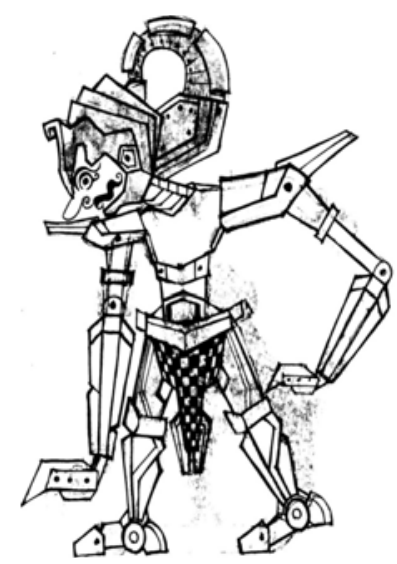

Gambar 9. Sketsa 1. (Sketsa: Gandar Setiawan, 2014)

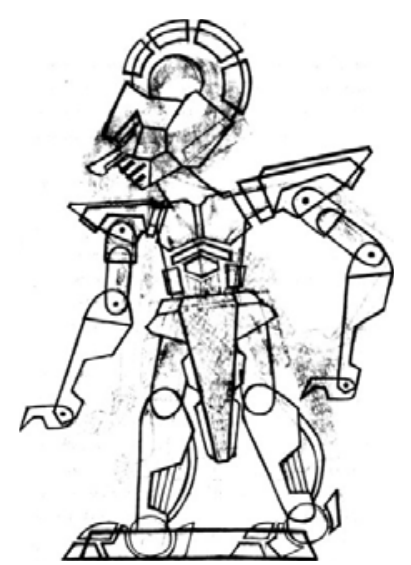

Gambar 10. Sketsa 3. (Sketsa: Gandar Setiawan, 2014) langkah dalam tahap perwujudan ini meliputi pemilihan bahan, teknik yang dipakai, dan wujud karya.

\section{Pemilihan Bahan}

Bahan yang digunakan adalah kayu mindi (lihat gambar 13), atau dalam bahasa latin disebut Melia azedarach. Kayu ini merupakan kayu yang berasal dari daerah tropis. Di Yogyakarta kayu mindi masih minim peminatnya. Karakter kayu ini yaitu memiliki warna dominan coklat muda, serat besar, dan memiliki serat yang cukup bagus. Kayu mindi termasuk dalam kategori kayu dengan kekerasan sedang.

Jenis kayu lainnya yang digunakan untuk pembuatan karya ini adalah kayu jati (lihat gambar 14) dan kayu kamper (lihat gambar 15). Kayu jati (Tectona grandia) termasuk dalam jenis kayu keras, memiliki karakter kayu ulet, berwarna coklat dan memiliki tekstur serat yang meliuk-liuk. Kayu ini mayoritas hidup di wilayah pulau Jawa, dan kualitas yang bagus berada di daerah Jawa Tengah dan Jawa Timur. Sedangkan kayu kamper merupakan

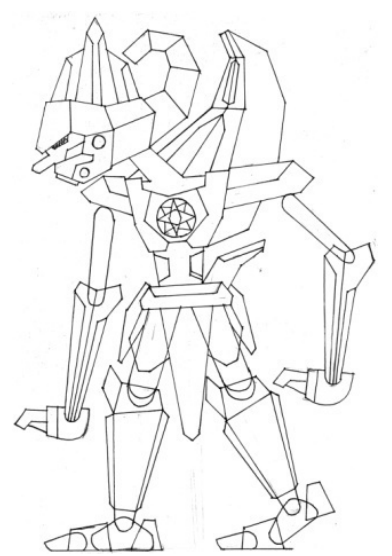

Gambar 11. Sketsa 4. (Sketsa: Gandar Setiawan, 2014)

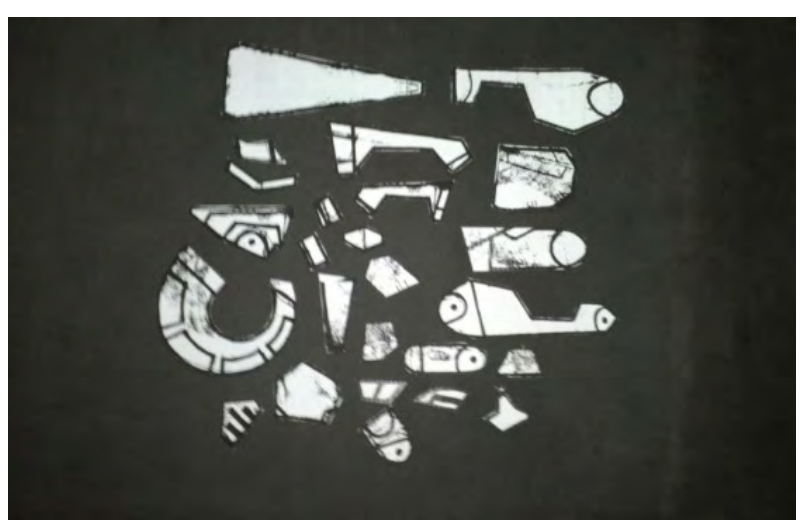

Gambar 12. Model potongan pola bagian robot. (Foto: Gandar Setiawan, 2014) 
kayu yang berasal dari daerah Kalimantan. Kayu ini memiliki warna merah kecoklatan. Termasuk dalam tingkatan kayu keras.

\section{Teknik yang Dipakai}

Teknik utama yang digunakan dalam pembuatan karya ini adalah teknik potong (cutting). Teknik potong menjadi teknik yang paling banyak digunakan dalam proses penciptaan karya ini. Penerapan teknik ini dilakukan menggunakan peralatan pendukung. Alat tersebut yaitu mesin gergaji skrol (scroll saw) dan gergaji bundar (circle saw). Kedua alat pemotong atau gergaji ini dapat dilihat pada gambar 16 dan 18 .

Gergaji bundar ini digunakan untuk memotong dan membelah kayu. Ukuran diameter mata

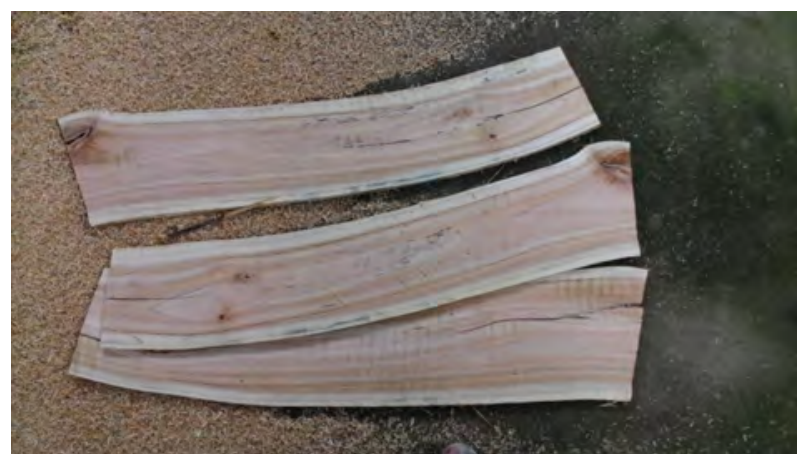

Gambar 13. Kayu mindi. (Foto: Gandar Setiawan, 2014)

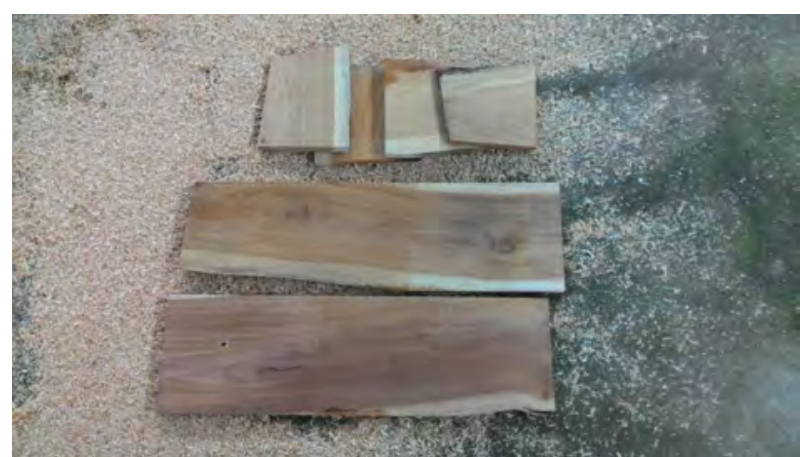

Gambar 14. Kayu jati. (Foto: Gandar Setiawan, 2014)

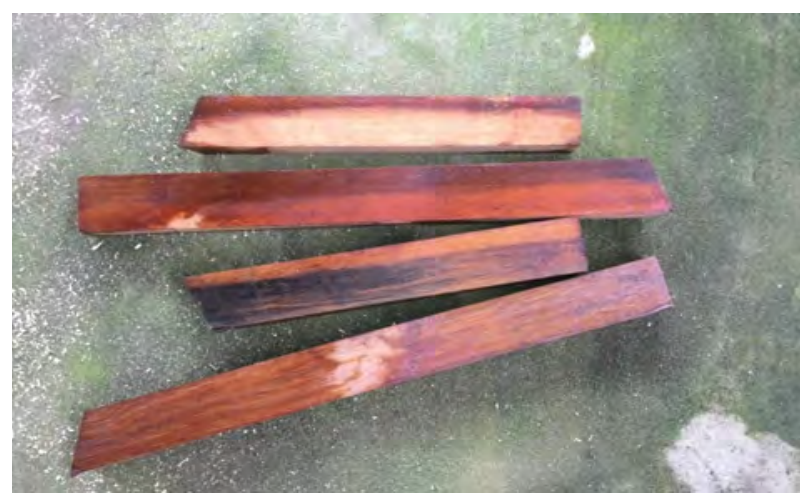

Gambar 15. Kayu kamper. (Foto: Gandar Setiawan, 2014) gergaji adalah 10 inchi dengan kapasitas kekuatan dinamo yang mampu berputar $20000 \mathrm{rpm}$.

Gergaji skrol ini merupakan modifikasi dari mesin skrol kecil. Alat ini menggunakan dinamo berkekuatan 1,5 tenaga kuda dan mampu berputar $5000 \mathrm{rpm}$.

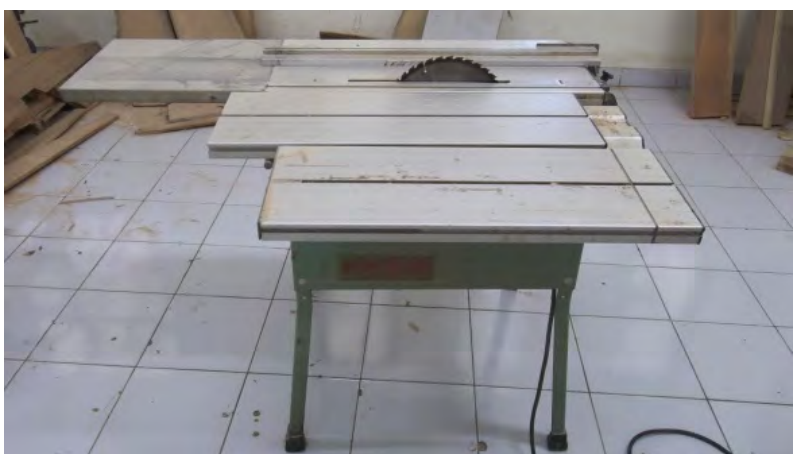

Gambar 16. Circle saw. (Foto: Gandar Setiawan, 2014)

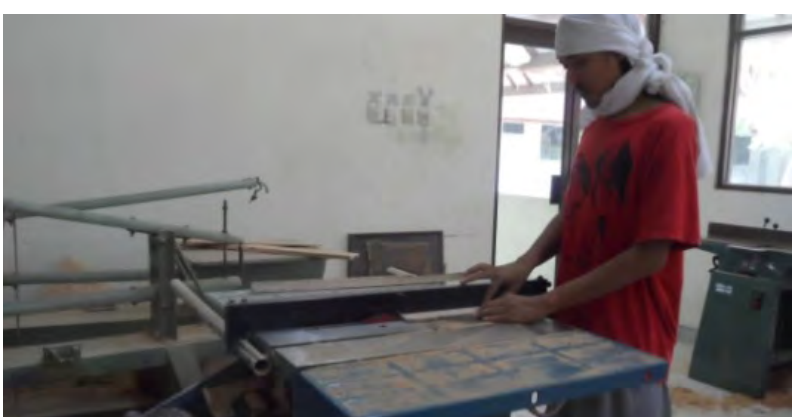

Gambar 17. Proses pemotongan kayu menggunakan circle saw. (Foto: Ecky Kartawitanto, 2013)

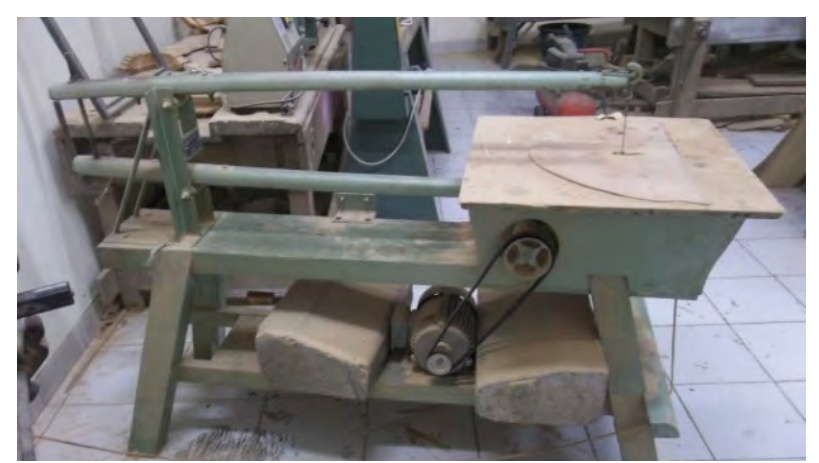

Gambar 18. Scroll saw. (Foto: Gandar Setiawan, 2014)

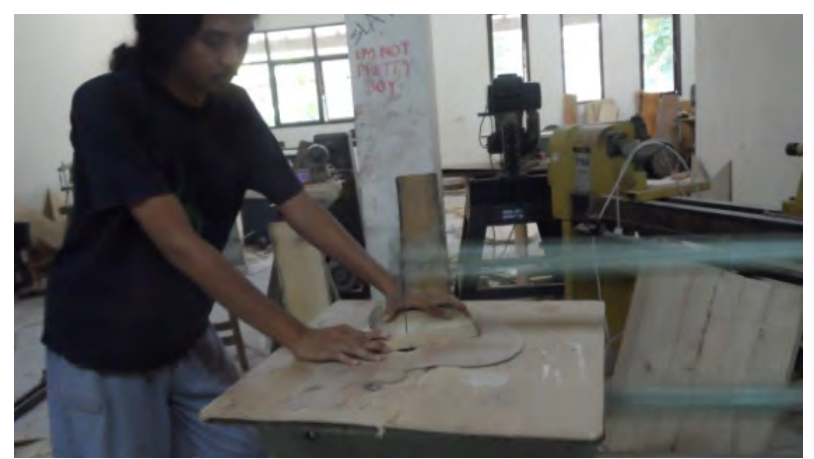

Gambar 19. Proses pemotongan kayu menggunakan scroll saw. (Foto: Ecky Kartawitanto, 2013) 
Dari hasil proses pemotongan kayu dengan menggunakan circle saw dan scroll saw, akan dihasilkan potongan-potongan yang siap untuk dirangkai. Setelah proses perangkaian selesai, dilanjutkan proses finishing yang meliputi penghalusan menggunakan amplas dan proses penutupan pori-pori kayu menggunakan sanding sealler. Proses selanjutnya yaitu pengamplasan ulang dan dilanjutkan pengecatan pada beberapa bagian saja sesuai konsep. Proses terakhir yaitu coating menggunakan clear gloss.

\section{Wujud Karya}

Gambar 20 adalah karya yang berjudul "Wrekudara". Karya ini berukuran 110x50x4 cm, berbahan dasar kayu jati, mindi, dan kayu kamper.

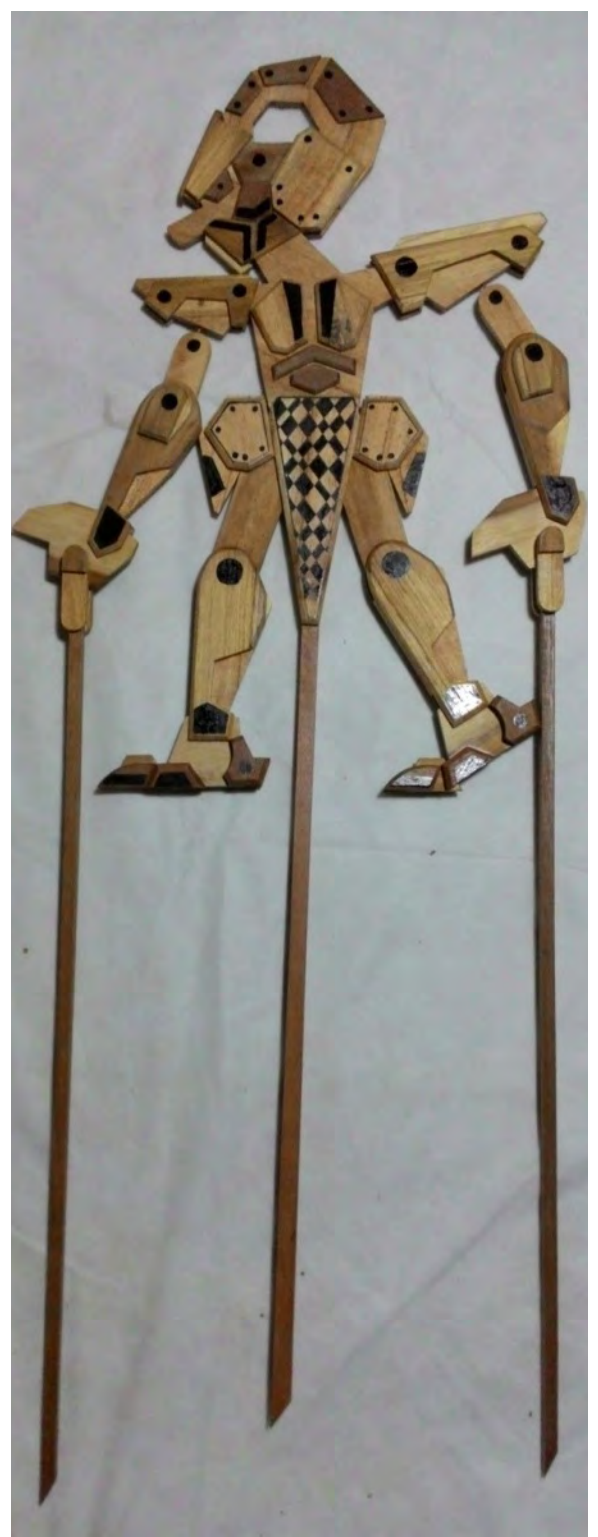

Gambar 20. Karya 1. (Foto: Gandar Setiawan, 2014)
Karya ini ingin menggambarkan sosok Wrekudara yang kuat dan perkasa. Untuk memperlihatkan tokoh Wrekudara karya dibuat berdasarkan karakter luarnya, yaitu memiliki senjata Kuku Pancanaka sebagai senjata yang khas dari Wrekudara, serta menggunakan dodot polèng bang bintulu.

Karya berjudul "Gatotkaca" (gambar 21), berukuran 100x50x4 cm. Berbahan dasar kayu jati, mindi, dan kayu kamper. Untuk memperlihatkan tokoh Gatotkaca karya dibuat berdasarkan karakter luarnya, yaitu memiliki kekuatan seperti besi yang diwakili oleh warna logamarna logam, karena Gatotkaca terkenal dengan julukan otot kawat balung wesi. Sedangkan karakter lain yang ingin ditunjukkan yaitu simbol bintang pada dada sebagai simbol dari kutang Antakusuma yang dapat digunakan untuk terbang dan melindungi diri.

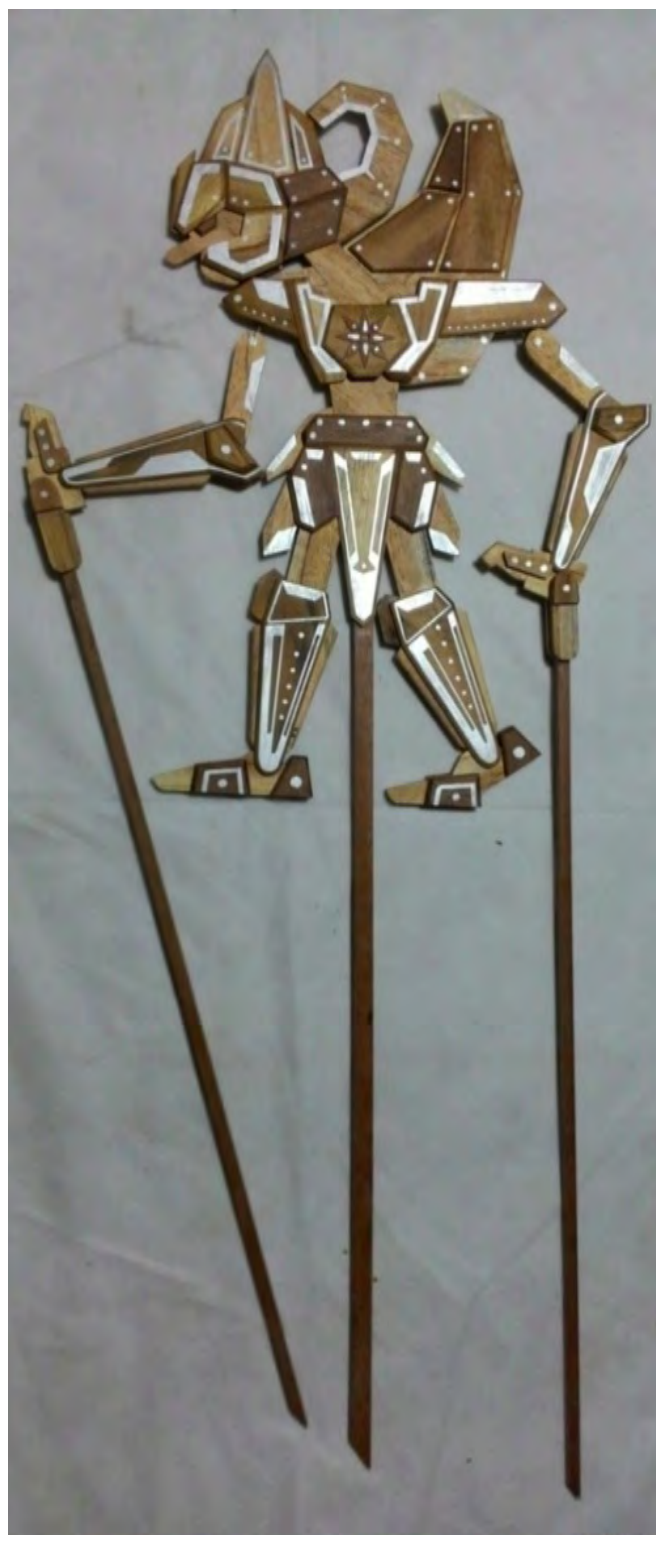

Gambar 21. Karya 2. (Foto: Gandar Setiawan, 2014) 


\section{Penutup}

Melalui proses yang telah dilakukan karya ini dapat terwujud. Bentuk yang dihasilkan yaitu wayang klithik robot tokoh Wrekudara dan Gatotkaca yang merupakan bentuk wayang yang dipadukan dengan bentuk robot. Karya ini menampilkan wayang klithik dengan karakter robot yang dapat dimainkan seperti layaknya wayang klithik pada umumnya. Dengan diciptakannya karya ini maka terjadi perpaduan unsur budaya tradisi dan modern, sehingga nilai-nilai tradisi yang ada pada karya muncul sebagai karakter khas Indonesia yaitu wayang.

\section{Kepustakaan}

Budiman, Kris. 2011. Semiotika Visual: Konsep, Isu,dan Problem Ikonisitas, Yogyakarta: Penerbit Jalasutra,.

Gustami, SP. 2004. Proses Penciptaan Seni Kriya: Untaian Metodologis, Yogyakarta: Program Pascasarjana S2 Penciptaan Dan Pengkajian Seni ISI Yogyakarta.

Liang Gie, The. 1997. Filsafat Keindahan. Yogyakarta: Adipura.

Lubis, Izwar. 2013. "Bahan Ajar Pendidikan Teknik Mesin dan Robotika", Sumber dari UPT Universitas Negeri Medan Sumatra Utara, Medan.

Kartika, Dharsono Sony. 2004. Seni Rupa Modern. Bandung: Rekayasa Sains.
Tim Penulis Sena Wangi. 1999. Ensiklopedi Wayang Indonesia jilid II. Jakarta: Sena Wangi.

\section{Webtografi}

http://crowsinside.blogspot.com/p/laman-unduh. html. Diakses pada tanggal 29 November 2014, jam 19.00 WIB.

http://ecx.images-amazon.com/images/ I/81AUEQixLmL._SL1500_.jpg. Diakses pada tanggal 23 Oktober 2014, jam 20.00 WIB.

http://gadgets.boingboing.net/2007/08/31/ashleywoods-bertie.html. Diakses pada tanggal 23 Oktober 2014, jam 20.00 WIB.

http://lostbrosclubhouse.com/wp-content/ uploads/2014/07/transformersautobots by_megavalve.jpg. Diakses pada tanggal 23 Oktober 2014, jam 20.00 WIB.

http://media-cache-ak0.pinimg.com/236x/e4/c5/ ba/e4c5ba436869041d732f34dc3861bca8. jpg, diakses 23 Oktober 2014, jam 20.00 WIB http://static.comicvine.com/uploads/ original/7/74798/1429066-so.jpg. Diakses pada 23 Oktober 2014, jam 20.00 WIB.

http://www.smosh.com/smosh-pit/photos/25amazing-wood-sculptures. Diakses pada tanggal 23 Oktober 2014, jam 20.00 WIB.

http://1.bp.blogspot.com/_8hg7KdpvuOY/TQnRilf7qiI/AAAAAAAAAOA/UoWi763We-s/ s1600/bima9.jpg. Diakses pada tanggal 29 November 2014, jam 20.00 WIB. 